\title{
A Study on the Achievement Motivation of High School Students in Ernakulam District of Kerala
}

\author{
Dr. Dhanya. N, Anitha. T. A \\ - Assistant Professor, Department of Home Science, St. Teresa's College, Ernakulam - 682035 \\ • Former Post graduate student in Child Development, Department of Home Science, St. Teresa's College, \\ Ernakulam - 682035
}

I. Introduction

Achievement motivation is defined as the need to perform well or the striving for success and evidenced by persistence and effort in the face of difficulties (Spencer, 1983). Achievement motivation is regarded as a central human motivation. According to Hilgard (1996) students may have the desire to achieve and ability to accomplish the task, but feel the accomplishment has little or no value and feel doing it is not worth the effort or time. Others may fear that they are not capable of completing the required task, so they do not even begin. They feel it is better to receive a lower over all grade than to prove that they do not have the ability to correctly complete the task. Spencer (1983) stated that achievement can often bring benefits and failure can often bring shame. Atkinson (1974) adds that is only a small number of students who fall in these categories of little accomplishment.

Achievement is relatively a new concept in the world of motivation (Thompson, 2003). It is now widely used and heard in the area of education. Achievement motivation refers to the tendency to strive for success or the attainment of desired art. According to Allan (2002) "Achievement motivation is conceived as a talent disposition which is manifested in overt striving only individual perceives performance as instrumental to a sense of personal accomplishment". Individuals high in achievement motivation are at their best when they can maintain a high level of involvement in ensuring the excellence of activities under their co-ordination or control. However they do relatively less well when required to manage excessive tasks or to function in highly stressful environment.

Achievement motivation is often correlated with actual achievement behaviour (Harter, 1986). The motivation to achieve how ever may evidence itself only in behaviour that children in different situations have different achievement attaining values for children (Eccles, 1998). Motivating students to achieve in school is a topic of great practical concern to teachers and parents, and of great theoretical concern to researchers. Higher education institutions are beginning to provide assistance to students especially new ones, in developing so called study skills and self-regulatory skills such as time management. One of the greatest challenges and opportunities of the $21^{\text {st }}$ century will be for schools at all levels to focus more on assisting students to became motivated in order that they can succeed in school. Student achievement has been widely researched over the past couple of decades. Several seminar works have contributed to our understanding of student achievement and what motivates students to learn.

The achievement of a person is very much related to the extent of motivation he or she has. Motivation as a factor of predicting achievement and found that motivation correlated more highly with achievement than did other factors. Motivation factors exert a profound influence on children's intelligence, performance and achievement not only in the laboratory but also in the classroom. Recent interest in high school student's levels of achievement has led to greater examination of the predictors that facilitate such performances. Colleges and Universities have become more selective in students admissions, not only examining high school academic records, but also student participation in extra curricular activities. The increasing attention given to understanding the characteristics that promote high levels of academic performance and expectations among high school students has led researchers to look beyond the confines of individual thought and examine the macro social influences that affect individual performances. The achievement motivation of schoolmates may create a learning environment that facilitates or impedes learning above and beyond what would be expected in the basis of individual students achievement motivation intelligence and background characteristics.

This study was thus undertaken to compare the overall achievement motivation between boys and girls and the need for achievement in the areas namely academic success, vocational achievement, social achievement and skill achievement. 


\section{Methodology}

The area selected for the study included various schools in Ernakulam city. The places were Aluva, Kaloor, and Fort Kochi. The sample chosen for the present study comprised of 50 boys and 50 girls (100 students) in the age group of 13-14 years selected through random sampling. The subjects were selected from four different schools in Ernakulam City namely Model technical Higher Secondary School, Kaloor, Ideal Public School, Aluva, Fatima Girls High School, Fort Kochi, St.George Britto High School, Fort Kochi. Two tools namely Self designed Questionnaire (2) Achievement Motivation Scale were used for the study.

The self designed questionnaire consisted of 17 questions to collect the background details of about the respondents like age, gender, father's occupation and mother's occupation, type of family and member of siblings etc. The questionnaire named 'Achievement Motivation Scale' was constructed and standardized by Beena (1986). The questionnaire contained 40 questions to assess the Academic Achievement, Vocational Achievement, Social Achievement and need for skill Achievement. It is a three-point scale and scoring was used to analyse the data. Each statement is followed by three alternative responses. The alternatives are arranged in order of one's inclination towards achievement in the areas academic, vocational, social context and skills weightage 1,2, and 3 were respectively awarded for alternatives (a), (b) and (c) respectively of any statement. The investigator first made visits to the selected schools; sought permission for the collection of data and selected the appropriate class (8th standard). Then the investigator briefed them on the purpose of the study and distributed the tools and collected them back after ascertaining that they were complete.

The data collected using the self-designed questionnaire was tabulated and consolidated and analysed using percentages. The data collected using 'Achievement Motivation Scale' was tabulated, consolidated, scored and statistically analysed using critical ratio.

\section{Background details of the respondents}

\section{Results and discussions}

Eighty four percent of the sample belonged to nuclear families and only 16 percent of the respondents belonged to the joint family. More than half of the respondents belonged to families that had four members $(63 \%)$. Only a very negligible percent $(2 \%)$ of families had seven members. One fourth of the family had 3 members (16\%). Sixty three percent of parents earned between Rs 8000-14000. Ten percent of the families studied earned still higher of Rs 14000 and above. Only 22 percent of those selected had an income between Rs.1000-8000. Thus majority of the subjects came from middle class and upper middle class families.

\section{Need for Academic success}

Mean scores of the two groups were computed to test the significance of difference between the mean values and is presented in table 1 .

Table 1. Academic success of boys and girls

\begin{tabular}{|l|l|l|c|c|c|}
\hline Category & N & M & SD & CR & $\begin{array}{c}\text { Level of } \\
\text { significance }\end{array}$ \\
\hline Boys & 50 & 21.86 & 3.2 & \multirow{2}{*}{3.02} & 0.01 \\
\hline Girls & 50 & 24.06 & 3.8 & & 0.01 \\
\hline
\end{tabular}

The above table shows the comparison of need for academic success of boys and girls. From the computed critical ratio given in the above table, it is evident that there is a significant difference in the need for Academic success of boys and girls. The difference between two categories is significant at 0.01 level. A close observation of the mean values obtained in this regard shows that boys $(\mathrm{M}=21.86)$ had low need for academic success when the mean scored compared to the girls $(\mathrm{m}=24.06)$ the higher mean score obtained by the girls indicate that they had better desire to achieve. The responses of the respondents showed that higher needs of Academic success are more optimistic and adaptable to life situations. In the modern era girls are no more restricted to the four walls of their homes. They have realized the importance of education and being independent. Their desire to excel in all fields of education and life has thus attributed to their strong desire in academic performance. Research has pointed out that nutritional orientations influence the study strategies students adopt which subsequently influence academic achievement while achievement goals emphasize the ways in which students think about themselves in learning. Intrinsic motivation reflects student's engagement in learning strategy and achievement.

\section{Need for vocational achievement}

Mean scores of the two groups were computed to test the significance of difference between the mean values and the results are given below. 
Table 2. Comparison of need for vocational achievement of boys and girls

\begin{tabular}{|c|c|c|c|c|c|}
\hline Category & N & M & SD & CR & $\begin{array}{c}\text { Level of } \\
\text { significance }\end{array}$ \\
\hline Boys & 50 & 21.6 & 2.9 & 2.4 & 0.05 \\
\hline Girls & 50 & 23.34 & 4.2 & & 0.4 \\
\hline
\end{tabular}

The above table shows that there is significant difference in the need for vocational achievement of boys and girls. The difference between two categories is significant at 0.01 level. A close relation of the mean values obtained in this regard shows that boys $(\mathrm{m}=21.6)$ had low need for vocation achievement when compared to the mean score of girls $(m=23.34)$ the higher mean score obtained by the girls shows their higher desirability for vocational achievement. The girls were more confident that they would have a bright future. Realizing the importance of being independent and being a contributor to the family, most girls of today's era prefers having a good job and also recognition and respect that comes after it. Parents also prefer their children to work .so as to lend a helping hand for the family. There fore even in this aspect girls have more desire for vocational achievement than boys.

Need for social achievement

Mean score of the two groups were computed to test the significance of difference between the mean values.

Table 3. Comparison of need for social achievement of boys and girls

\begin{tabular}{|l|l|l|c|c|c|}
\hline Category & N & M & SD & CR & $\begin{array}{c}\text { Level of } \\
\text { significance }\end{array}$ \\
\hline Boys & 50 & 20.66 & 3.4 & 2.06 & 0.05 \\
\hline Girls & 50 & 22.44 & 5.1 & 2.06 \\
\hline
\end{tabular}

The above table shows that there is significant difference in the need for social achievement of boys and girls. The difference between two categories is significant at 0.01 level. A close observation of the mean values obtained in this regard shows that boys $(\mathrm{m}=20.66)$ had low need for social achievement when the mean score is compared to girls $(\mathrm{m}=22.44)$ The higher mean obtained indicated that they are willing to do social work to serve the society. In the words of Guilford "A native is a particular internal factor on condition that tends to initiate and to sustain activity". Thus motivation includes all those internal conditions, which begin activity or sustain it. The responsibilities of girls is not only looking after the family or work, however most girls who share the responsibility in the social life, such as women's welfare, charitable programme, Self Help Groups etc. This enables girls to interact and to help each other. Thus again girls are seen to be more motivated for social achievements than boys. Individuals with high motivation to achieve are more likely to succeed in society and other fields of their career. The value of a task of an individual includes the importance of doing well on the task, the usefulness of a task for future goals (Schunk, 1983). From the above findings it is clearly shown that girls had high desire for social achievements than boys because they have self-perception of their ability and the confidence to achieve the desired outcome.

\section{Need for skill achievement}

Mean score of the two groups were computed to test the significance of difference between the mean values.

Table 4. Comparison of need for skill achievement of boys and girls

\begin{tabular}{|l|l|l|c|c|c|}
\hline Category & N & M & SD & CR & $\begin{array}{c}\text { Level of } \\
\text { significance }\end{array}$ \\
\hline Boys & 50 & 19.9 & 3.0 & \multirow{2}{*}{2.9} & 0.01 \\
\hline Girls & 50 & 22.7 & 2.7 & & 0.7 \\
\hline
\end{tabular}

The statistical analysis shows that there is significant difference in the need for skill achievement of boys and girls. The difference between two categories is significant at 0.01 level. The mean values obtained show that boys $(M=19.9)$ were less interested in skill achievement as compared to girls $(M=22.7)$. The higher mean score indicated that they have higher desire for skill achievement. The girls have consistent attitudes and systematic method of working when compared to boys. Their skillfulness has also matched with boys in almost all fields of education. Today there is more opportunities for developing the skills and talents of youths in many training centers, colleges etc. These have helped them in acquiring jobs and enhancing being self-employed. The above reasons thus suggest the high motivation for skill achievement than boys. The above investigation shows that girls are highly desire for skill achievement than boys. In recent years there are various opportunity for girls and they want to explore their skills than boys. 


\section{Comparison of overall achievement motivation of boys and girls.}

The following figure deals with the overall comparison of achievement motivation of boys and girls to find out that whether there was any significant difference. The mean scores of the two categories were computed to test the significance of difference between the mean values.

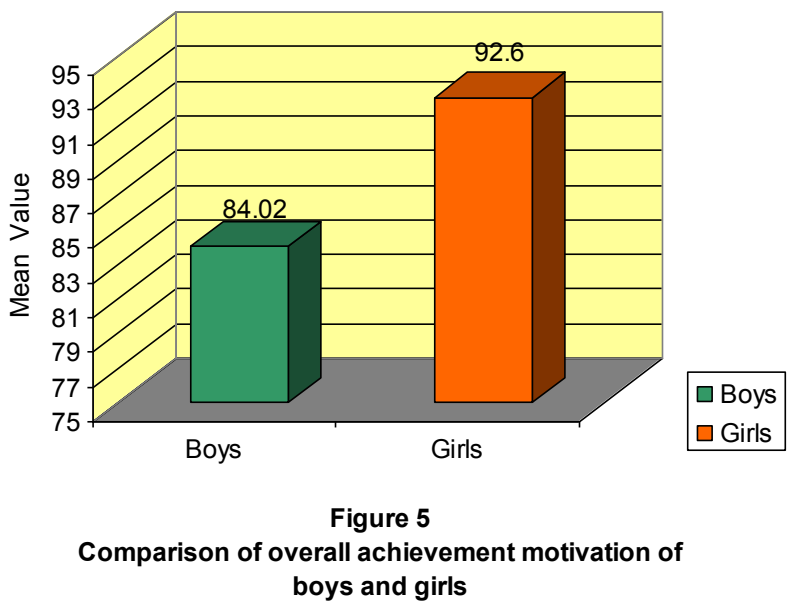

The above figure shows that there is significant difference in the overall achievement of boys and girls. A close observation of the mean value obtained in this regard shows that boys $(\mathrm{M}=84.02)$ had low need for overall achievement when the mean score is compared to girls. $(\mathrm{M}=92.6)$ The higher mean value indicated that girls have more desire for achievement. In current scenario most of the girls have the desire to excel in all fields of education and life. Most of the girls prefer having a good job and also recognition and respect from the society. Thus girls have higher desire for overall achievement than boys. Most of the earlier studies pointed out that girls and boys have equal desire for achievement. During the conduct of the test for achievement, girls lost their confidence and their scores were the same as those of boys, which was attributed to the environmental changes by the researcher that is when they were moved away from the class room, the familiarity was replaced with uncertainty which led to increase in stress. Confidence being a predictor of scores in achievement tests was affected which led to decrease in scores.

\section{Conclusion}

It is clear that the girls are more desire to achieve than boys. Their need for academic success is also high and influenced by all other achievements such as vocational, skill and social achievement. In the modern era girls no more restricted to the four walls of their homes. They have lot of opportunities to perform and to show their ability. Parents also prefer their children to work. So girls also considered as a helping hand for the family. Due to these reasons most of the girls have strong desire for achievement.

\section{References}

[1]. Allan, W. E;(2002). Annual Review of Psychology, Vol.53, Pp: 109-132.

[2]. Atkinson, J.W;(1998). Motivational determinants of risk taking behaviour, psychological review, vol.64, Pp.359-375.

[3]. Eccles, J.S., (1991). Sex difference in Achievement Pattern, Volume 32. Pp. 97-132.

[4]. Harter, S; (1982). The perceived competence scale for children; Child Development, Vol. 83, Pp .87-97.

[5]. Hilgard, E. R; (1996). Introduction to Educational Psychology, New York: Stanford University publishers

[6]. Schunk, D. H; (1996). New Motivation in education Theory, Research and application, New York: Merrill Prentice Hall Publishers.

[7]. Spencer; (1983). Introduction to psychology, New York: Hilgard publishers.

[8]. Thompson, G; (2003). Behaviour modification, New York: Prentice Hall Publishers. 